\title{
The Influence IT Governance Mechanism on Effectiveness ITG and IT Performance: A Partial Least Squares Structural Equation Modeling Approach (PLS-SEM)
}

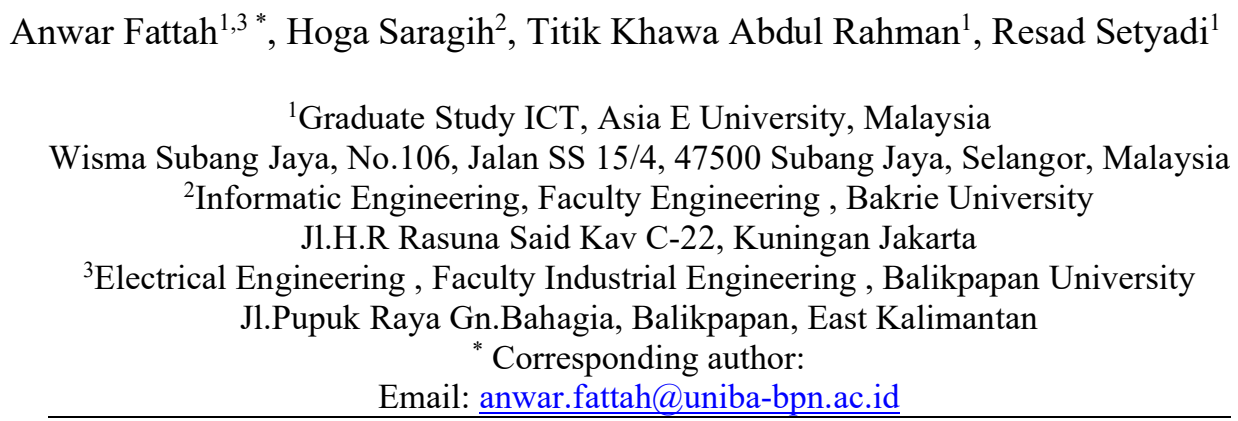

\begin{abstract}
.
This article presents raw inferential statistical data that determine the IT Governance effectiveness on the IT Performance.To identify influence mechanism Information Technology Governance (ITG) on Effectiveness ITG and IT Performance.Data were collected from respondents in all regions of Indonesia. Quantitative research methods are used to analyze data. The structured questionnaire was distributed to respondents in all regions of Indonesia who understood the field of IT Governance in Higher University whose reliability and validity were confirmed. Structural equation modeling (SEM) using Smart PLS software, version 3, is used to present data. SEM path analysis shows an estimate of the relationship of the main constructs in the data The results obtained from this dataset shows positive relationship between mechanism Structure, Process and Relation to IT Governance effectiveness, consciousness also has a significant influence on the IT Performance and positive relationship between IT Governance effectiveness and IT Performance. However, mechanism structure and process has proven to have a negative and insignificant influence on the IT Performance Effective IT governance related to mechanism ITG and IT Performance level of unit analysis. One of the more significant findings to emerge from this study is that evaluate the mechanism ITG impact to effective IT governance that focus on higher education institution (HEI). This study already examines a validation of evaluation model and collecting data in particular higher education institution (HEI) as a single case study.

Keywords: IT Governance effectiveness,IT Performance, Mechanism ITG, Structural Equation Modeling
\end{abstract}

\section{INTRODUCTION}

Information Technology (IT) is a very important aspect for higher education institutions (HEI) in both teachings, research, and administration. The managers of those intuitions are more and more aware that IT is a strategic tool for their institutions. On the other hand, IT Governance is getting attention from the practitioner and research side, given the need to govern IT extending the organization's strategy and objectives into IT. IT Governance helps to set clear expectations, to gain participation, open communications, establish accountability, and provide executive management oversight. Information technology governance (ITG), essentially defined as a set of decision-making structures, processes, and relational mechanisms [1] is an organizational capability that plays a significant role in value delivery from 
information technology (IT) investments [2]-[4]. Introduction section can include background information such as theories, prior work, and hypotheses. Higher education institutions, in special universities from many countries, have increasingly recognized the importance of IT governance[5]. To control this heterogeneous set of technologies, effective IT governance is critical creating use of structures, processes and relative mechanisms. According to [6] Complex and decentralized organizations, such as universities, should frequently review their IT governance mechanisms to deal with innovation and changes in their environment and adapt to new technologies. A framework of IT governance may be deployed with a set of the mechanisms such as structures, processes, and relational mechanisms [3][4][7][8][9]. The effective and efficient use of IT at universities to support research, teaching and management requires appropriate ITG[5], [6], [10]-[13]. Effective ITG in universities is strongly associated with a high level of maturity of IT governance mechanisms[14]. Moreover, the adoption of formal practices at the highest level of the organization for governing IT, as claimed by [15], [16], is expected to bring benefits and improve organizational performance. Effective IT governance is crucial for an organization to achieve its corporate performance goals. To implement IT governance effectively, a set of IT governance mechanisms is required (e.g., IT steering committee, IT organizational Structure) that encourages behaviors congruent with the organization's mission, strategy, values, norms and culture [6], [7] Previous studies examining the effectiveness of IT governance mechanisms have produced interesting results [11][13]. A mechanism that may be suitable for an organization in the financial industry may not be suitable for an organization in another industry [14]-[16] have identified a baseline of IT governance mechanisms for Belgium's financial industry. Pereira et al. provided ITG mechanisms for the Portuguese financial industry[17] and healthcare industry [18]. These outcomes show that baseline mechanisms differ across industry sectors. The need to address the analyze of effective ITG mechanisms in different contexts encourages further studies especially Higher education sector.

\section{LITERATURE REVIEW}

\section{Mechanism Information technology Governance}

ITG involves a set of high-level definitions, such as principles, values, and goals, operationalized through mechanisms. Several authors argue that enterprises should implement ITG over the use of IT mechanisms [19], [20]. An ITG framework may be deployed using a set of mechanisms including structure, processes, and relational mechanisms [21],[22][23] Researchers[24],[3], [22], [25] Propose that IT Governance can deploy enterprise governance of IT by using a holistic mixture of various structures, processes, and relational mechanisms. Effective IT governance is crucial for an organization to achieve its corporate performance goals. To implement IT governance effectively, a set of IT governance mechanisms is required (e.g., IT 
steering committee, IT organizational structure) that encourages behaviors congruent with the organization's mission, strategy, values, norms and culture [26].

\section{Structure mechanism}

Structure mechanism are responsible for defining roles and responsibilities for making IT decisions and for enabling contacts between business and IT management decision-making functions. Steering committees are an example of those structures composed of directors, managers and executives, in other words, people responsible for decision-making in the organization[20][22][27].[7], in research conducted in 256 public and private organizations around the world, found that different structural configurations bring different results for domain decisions related to IT principles, IT architecture, IT infrastructure, business and investment applications, and prioritization. In other studies focusing on specific practices related to decision-making structures, however, authors have not found positive effects in terms of the use of decisionmaking structures. [8], for example, did not find a positive correlation in Australian public organizations between strategic committees and IT governance effectiveness.However, as pointed out by [8], these results maybe due to the low maturity of organizations dealing with the formalization of roles and responsibilities for making IT decisions. Also, according to [28], organizations suffer from incomplete implementations of ITG mechanisms in practice, leading to suboptimal results.

\section{Process mechanism}

Process mechnism involve the arrangement of formal decision making and the design of the forms for monitoring that the executing of IT operation is following the rules. Monitoring also provides inputs to decision making as re-gards investment proposals and evaluation processes, ar-chitecture exception processes, service levels agreements, chargeback, and other metrics. [22], [25], [27]. Relational mechanism include the active participation of, and collaborative relationships among, corporate executives, IT Management, and business management. Appropriate communication and knowledge sharing with learning and coaching is important [22], [25], [27]

\section{Effectiveness ITG}

The study of the effectiveness of IT governance mechanisms has resulted in the results of studies on how IT governance mechanisms affect the effectiveness of information technology governance [4], [26], [29]. Research by [30] examines the relationship between three governance mechanisms - the IT steering committee, the IT solution manager, and the IT investment portfolio management process and the effectiveness of IT governance. Using the method of sending questionnaires to 180 federal government employees, the results of the study show that there is a positive correlation between the IT steering committee and the IT solution manager and the effectiveness of IT governance. Meanwhile, the IT investment portfolio management process has a negative correlation with the effectiveness of IT governance. [4] surveyed the CIOs of 256 companies in the US and identified fifteen of the most common IT governance mechanisms. Among these are the senior management 
committee (IS Steering Committee), the IT Executive Commission, the Architectural Commission, etc. [14] using 80 Auditors in Queensland, Australia, conducted a study to determine the effectiveness of IT governance mechanisms, revealing that the existence of three mechanisms (IT Steering Committee, senior management involvement in IT, and company performance measurement systems are positively correlated with the effectiveness of IT governance. On the other hand, two other mechanisms (centralization of IT decision making and the position of IT functions within the organization) are not supported The study [14], uses only a relatively small sample size and involves one ISACA Chapter (Queensland Chapter), thereby limiting the external validity of the study results.

[31]investigated information technology (IT) governance mechanisms in public sector organizations. They find that an effective IT strategy committee and a communication system that effectively disseminates policies and procedures both have a significant positive influence on the overall level of IT governance effectiveness while the IT Steering Committee, senior management involvement in IT, ethics/propriety culture, and measurement systems company performance has a negative effect on this study. [29]Develop studies related to effective information technology governance. This study seeks to empirically examine the IT governance mechanisms that affect the overall effectiveness of information technology governance. Furthermore, this study examines the relationship between effective IT governance and IT outsourcing decisions in organizations, and the level of IT Intensity in the organization. [32] shows that there is a positive relationship between the effectiveness of information technology governance and information technology performance. Assessing an enterprise or business unit governance performance by evaluating the effectiveness of IT governance in delivering foru objective weighted by their importance to the enterprise [33]

- $\quad$ Cost effective use of IT

- $\quad$ Effective use of IT for asset utilization

- $\quad$ Effective use of IT for growth

- $\quad$ Effective use of IT for business flexibility

\section{Information Technology Performance}

IT governance performance is the level of IT governance effectiveness or how effective IT governance is, that is, the regulation encourages the desired organizational behavior and ultimately the achievement of performance goals in the organization [33]-[36]. Effective IT governance requires senior managers to define the goals of company performance, and actively design governance that facilitates habits that fit those goals. This performance can be measured by the value of services provided by the IT organization from a business point of view. The easiest way to measure such performance in organizations was reported in a study by [7]. According [13] IT governance mechanisms is to enhance business/IT alignment with the positive association of IT governance performance. The impact of IT on organizational 
performance [21], [37] argues that IT performance is characterized by a high level of effective IT governance structures and processes [38] found a strong positive relationship between IT governance implementation and organizational performance.[39] do not find a direct effect of IT governance on IT investment performance, however, IT governance moderates the relationship between IT capital and IT investment. The study of [40] studied the correlation between IT governance and IT performance. Study of learning from practitioner experience came up with several ITG mechanisms that best describe the effectiveness of a tertiary institution in Malaysia. This evaluation model of effective IT Governance and Performance IT is derived from past studies [16], [36], [42]. In order to confirm the model, the significances of the relationship among the variables need to examine as the next step from this study. The proposed research model that will be used to examine the effective IT governance and Performance of Information technology can be seen as following

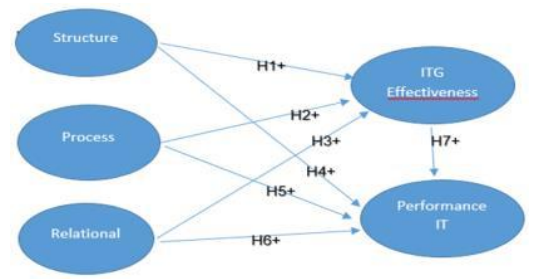

Fig. 1. ITG Effectiveness Model

\section{A. Conceptual Model and Hypotheses}

The conceptual model and hypotheses referred to the revisited ITG Effectiveness Model model in Fig. 1. This research did use the contextual variable, namely, type of information since we focus on the information stakeholder governance stakeholder in HEI. Based on the model previously explained in Fig. 1, the description of each variable used in this study is explained in Table 1.

Table 1.Varible Mechnism ITG, It Governance Effective Ness, It Performance

\begin{tabular}{ll}
\hline Area & Sub Area \\
\hline necha & - IT Steering Committee providing guidance and direction on its architecture and \\
Structu & service standards (MS1). \\
re (MS) & Education (Rector, Chairman, Director, Dean, etc.) ensures IT issues are handled \\
& appropriately and in accordance with the planning perspective. (MS2). \\
& - Information System Center or IT Support Agency/Unit serves in building, \\
& monitoring and maintaining information technology systems and services (MS3). \\
& - The Head of the Information System Center or the head of an IT Support \\
& Institute/Unit plays a major role in implementing IT Governance in universities \\
& (MS4) \\
& - The Head of Information System Center or the head of an IT Support Unit has a \\
& direct reporting line to rector/chairman/director/dean/chief financial officer (Vice \\
& Rector II of Development and Finance, Vice Chairman II of General and Financial \\
& Fields, or Similar Office) (MS5) \\
& - Audit Committee at the level of the executive officer of the Higher Education is
\end{tabular}


required to develop IT Audit activities (MS6)

- Strategic Planning Information System is a formal process in determining

Mecha universities in identifying strategic applications and aligning organizational nism strategies with effective information systems in achieving college goals (MP1)

Process -IT Governance Framework (MP2)

(MP) -Organizational Performance Measurement System (OPMS) is an important relationship between the vision/mission of the College and the involvement of effective IT departments in measuring performance such as IT Balance Score Card, IT back Charge (MP3)

-IT Budget Control \& Reporting Process (MP4)

Mecha -Corporate Communication System implements increasing awareness of nism understanding, knowledge, framework, responsibilities and duties of IT governance Relatio (MR1).

nal -Informal meeting between business and IT executive / senior management) (MR) discusses the activities and direction of IT development of universities institutions (MR2)

-Cross functional business/IT Training): Training conducted by organizations / companies related to information technology (MR3)

-Portfolio and business project management/IT bridges the gap between business and IT objectives (MR4)

IT -Understanding of Business Plan to achieve organizational objective (ITP1)

Perfor -Background/capabilities in IT (ITP2)

mance -Network IT infrastructure, internet and application systems (ITP3)

(ITP) -Innovations in preventing security problems System / IT (ITP4)

-IT Application System (ITP5)

-The Head of information system center (PSI) or IT Support Agency/Unit often communicates needs (ITP6)

-The Head of information system center (PSI) or IT Support Agency/Unit always provides a preventive way to anticipate mistakes that have occurred (ITP7)

-Meeting between the IT Steering Committee, (Head of information systems center (PSI) or IT Support Institute/Unit) and IT Strategy Committee at the level of the executive officer of the College (ITP8)

-IT Business Process has been done on measurement (IT balance Score Card/ROI/VALIT/Critical Success factor (CSF) /Service level Agreement (SLA) (ITP9)

-Training on IT/ application systems in higher education (ITP10)

-Basic knowledge and understand the importance of the usefulness of information technology in the organization (ITP11)

IT -Effective use of IT for cost savings (ITG1)

Govern -Effective use of IT for asset utilization (ITG2)

ance -Effective use of IT for growth (ITG3)

Effecti -Effective use of IT for business flexibility (ITG4)

veness

(ITG)

H1. Structure mechanism has a positive effect on Effectiveness information technology governance (ITG).

H2. Process mechanism has a positive effect on Effectiveness information technology governance (ITG). 
H3. Relational mechanism has a positive effect on Effectiveness information technology governance (ITG).

H4. Effective information technology governance (ITG) has a positive effect on Information technology Performance

H5. Structure mechanism has a positive effect on Performance information technology

H6. Process mechanism has a positive effect on Performance information technology

H7. Relational mechanism has a positive effect on Performance information technology

\section{B. Questionnaire Development}

Preliminary data were obtained through literature studies, as seen in Table 1. From the literature studies obtained later developed into a questionnaire. The questionnaire through an online survey can be accessed at the URL https://bit.ly/2Xrpjzf , this questionnaire is then distributed to various communities that understand higher education the field of IT Governance in all regions of Indonesia, as many as 139 copies of questionnaires are included, through a selection and feasibility process taken only 129 copy $(92.8 \%)$. The survey questionnaire was chosen because it was considered the most preferred technique because of its many advantages and good quality[43].

\section{Measurement Model}

To meet the quality feasibility, this data is then analyzed by considering the values: Cronbach's Alpha (0.6), Composite Reliability (0.7), AVE (0.5) and Loading Factor (0.7) [44], [45]. To determine the level of a significant path coefficient, the bootstrap and T-Statistic processes are used above 1.96 at the $95 \%$ confidence interval [45].The data presented is based on qualitative and quantitative research. Qualitative data were obtained based on literature studies to obtain awareness variables, as seen in Table 1 . While quantitative data were obtained by distributing questionnaires to respondents. The survey method is considered as the right data collection method.

\section{RESULT AND DISCUSSION}

Produce information answering important variable questions that influence the IT Governance effectiveness and IT Performance. Respondents in the Indonesian country were selected for this study. To test the data, researchers propose a model where Mechanism Structure, Mechanism Process and Mechanism Relational are outcome variables. The model proposed by the researcher must be tested for validity from the proposed model and to determine whether the data, which has been collected in the field, matches the proposed conceptual model. The quality of the measurement model is determined based on its validity and reliability [44], [45]. The results of testing the validity and reliability of the data are shown in Table 2. 


\section{A. Part Model}

Table 2. Mesurement Accuracy Assessment

The PLS estimation results for the structural model, path coefficients values as

\begin{tabular}{|c|c|c|c|c|c|}
\hline $\begin{array}{l}\text { Research } \\
\text { Construct } \\
\mathrm{S}\end{array}$ & $\begin{array}{l}\text { PLS } \\
\text { code item }\end{array}$ & $\begin{array}{l}\text { Cronbach's } \\
\text { Alpha Value }\end{array}$ & $\begin{array}{l}\text { Composite } \\
\text { reliability }\end{array}$ & $\begin{array}{l}\text { Average } \\
\text { variance } \\
\text { extracted } \\
(\mathrm{AVE})\end{array}$ & $\begin{array}{l}\text { Factor } \\
\text { loading }\end{array}$ \\
\hline \multirow[t]{3}{*}{ MS } & MS1 & 0.716 & 0.840 & 0.637 & 0.700 \\
\hline & MS3 & & & & 0.857 \\
\hline & MS4 & & & & 0.829 \\
\hline \multirow[t]{4}{*}{ MP } & MP1 & 0.795 & 0.866 & 0.619 & 0.812 \\
\hline & MP2 & & & & 0.741 \\
\hline & MP3 & & & & 0.764 \\
\hline & MP4 & & & & 0.826 \\
\hline \multirow[t]{3}{*}{ MR } & MR1 & 0.715 & 0.840 & 0.637 & 0.749 \\
\hline & MR3 & & & & 0.804 \\
\hline & MR4 & & & & 0.839 \\
\hline \multirow[t]{4}{*}{ ITG } & ITG1 & 0.822 & 0.882 & 0.651 & 0.719 \\
\hline & ITG2 & & & & 0.850 \\
\hline & ITG3 & & & & 0.814 \\
\hline & ITG4 & & & & 0.840 \\
\hline \multirow[t]{8}{*}{ ITP } & ITP3 & 0.912 & 0.930 & 0.655 & 0.800 \\
\hline & ITP4 & & & & 0.833 \\
\hline & ITP5 & & & & 0.742 \\
\hline & ITP6 & & & & 0.877 \\
\hline & ITP7 & & & & 0.759 \\
\hline & ITP8 & & & & 0.751 \\
\hline & ITP10 & & & & 0.842 \\
\hline & & & & & 0.811 \\
\hline
\end{tabular}

well as the item loadings for the research constructs are shown in Fig. 2 (Table 3). The main data source (questionnaire) is used to collect data from respondents in the territory of Indonesia. The Microsoft Excel spreadsheet worksheet is used to enter all data and draw conclusions from the data obtained. The Smart PLS software for structural equation modeling techniques (SEM) is used to record data and carry out the statistical analysis. In addition, Smart PLS supports exploratory and confirmation research; normal multivariate and good for small sample sizes. 


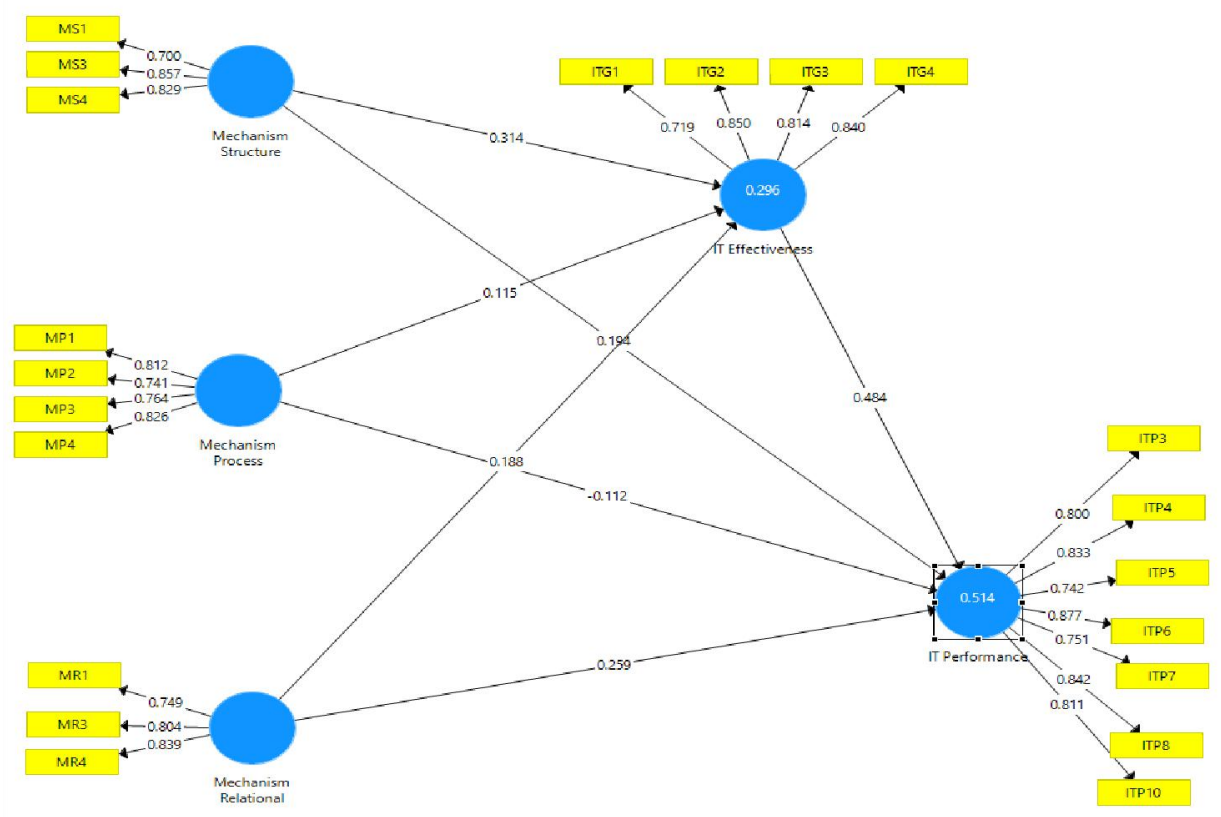

Fig. 2 Measurement and structural model results

Table 3

OUTCOMES OF STRUCTURAL EQUATION MODEL ANAKYSIS

Path Hypothesis Part T-

Decision

Coefficient statistics

( $\beta)$

\begin{tabular}{llccc}
\hline Mechanism Structure -> & $\mathrm{H} 1(+)$ & 0.314 & $2.302^{* *}$ & Positif and \\
ITG Effectiveness & $\mathrm{H} 2(+)$ & 0.115 & 0.902 & Significant \\
Mechanism Process -> & $\mathrm{H} 3(+)$ & 0.188 & $1.790^{*}$ & Positif and \\
ITG Effectiveness & $\mathrm{H} 4(+)$ & 0.194 & 1.637 & insignificant \\
Mechanism Relational -> & $\mathrm{H} 5(+)$ & -0.112 & 1.063 & Positif and \\
ITG Effectiveness & $\mathrm{H} 6(+)$ & 0.259 & $2.524^{* *}$ & significant \\
Mechanism Structure -> & $\mathrm{H} 7(+)$ & 0.484 & $6.377^{* *}$ & Positif and \\
ITG Performance & & & & insignificant \\
Mechanism Process -> & & & & Negatif and \\
ITG Performance & & & & insignificant \\
Mechanism Relational -> & & & & Positif and \\
ITG Performance ITG & & & & Significant \\
Effectiveness_ -> IT & & & & Positif and \\
Performance & & & & Significant \\
\hline
\end{tabular}

*T-statistics above 1.96 two-tailed $>0.05$

* T-statistics above 1.64 one-tailed $>0.025$ 


\section{B. Hypotheses Testing}

Path analysis focuses on the estimated value in Standardized Regression Weights to determine the variables' positive or negative relationship. The p-value and CR on the Regression Weights are used to determine the significant level between the two variables. If the estimated value is positive then the two variables have a positive relationship; conversely, if the estimated value is negative then the two variables have a negative relationship. To test the significant relationship between two variables, the $\mathrm{CR}$ value must be more than 1.96, and the p-value is less than 0.05 ; conversely, if the $\mathrm{p}$-value is more than 0.05 and the $\mathrm{CR}$ value is less than 1.96, then both variables do not have a significant relationship. Details of the hypotheses test results are shown in Table 3.

H1 (Structure Mechanism will have a positive effect on ITG effectiveness) is accepted. The results indicated that concern for Structure mechanism had a significant relationship with ITG effectiveness on HEI (T-Statistics $2.302>1.96$ ). Mechanisms structure appear to be more effective among universities such IT Steering Committee, IT Strategy Committee. This hypothesis's results are consistent with a study conducted by [42],[8], [29],[26],[46],[30] who found that Mechanism structure in IT Steering Committee, IT Strategy Committee have positive effect ITG. The Head of the Information System Center/IT Organizational Structure defining roles and responsibilities for making IT decisions and for enabling contacts between business and IT management decision-making functions. [47][29], [34],[26] who found that The Head of the Information System Center/IT Organizational Structure have positive effect ITG.

H2 (Process mechanism will have a positive effect on ITG effectiveness) is rejected. The results indicated that concern for Process mechanism had insignificant relationship with ITG effectiveness (T-Statistics $0.902<1.96$ ). ITG effectiveness on HEI.. This hypothesis's results are consistent with a study conducted by [8], [29] who found that Mechanism Process in Cooperate performance measurement system have negative effect ITG. From this research indicate that Mechanism process not support for effectiveness IT Governance in HEI because Respondents not understand how the process mechanism is implemented and measurements are taken such us ITG framework, Strategic Planning also IT Budget Control \& Reporting Process.

\section{H3 (Relational Mechanism will have a positive effect on ITG effectiveness)}

is rejected. The results indicated that concern for relational mechanism had insignificant relationship with ITG effectiveness on HEI (T-Statistics $1.790>1.64$ ). This hypothesis's results are consistent with a study conducted by [47][29] who found that Relational Mechanism em have positive effect ITG. From this research indicate that Relational Mechanism support for effectiveness IT Governance in HEI because Universities should be able to create an atmosphere cooperation between units. Synergy between units must be able to created. In addition, when there are several campuses in one college, communication between units as well established. 
H4 (Structure Mechanism will have a positive effect on IT Performance) is rejected. The results indicated that concern for structure mechanism had significant relationship with ITG Performance on HEI (T-Statistics $1.637<1.96$ ). This hypothesis's results are consistent with a study conducted by [48] who found that Structure Mechanism have negative effect IT Performance.

H5 (Process Mechanism will have a positive effect on IT Performance) is rejected. The results indicated that concern for process mechanism had insignificant relationship with ITG Performance on HEI (T-Statistics $1.063<1.96$ ). This hypothesis's results are consistent with a study conducted by [48] who found that process mechanism have negative effect IT Performance.

H6 (Relational Mechanism will have a positive effect on IT Performance) is accepted. The results indicated that concern for process mechanism had significant relationship with ITG Performance on HEI (T-Statistics 2.425>1.96). This hypothesis's results are consistent with a study conducted by [48] who found that Relational mechanism have Positive effect IT Performance.

H7 (ITG Effectiveness will have a positive effect on IT Performance) is accepted. The results indicated that concern for process mechanism had significant relationship with ITG Performance on HEI (T-Statistics 6.377>1.96). This hypothesis's results are consistent with a study conducted by [48] who found that ITG effectiveness have Positive effect IT Performance.

The data presented in this article have implications for academics, for example, IT Governance Effectiveness directly influences the IT Performance in a positive and significant way as indicated by the path coefficient of $(\beta=0.484)$. Therefore, for academics in the field of IT Governance, this discovery can enhance their understanding of the relationship between IT Governance Effectiveness and IT Performance. This is a useful contribution to be used as literature. On the practitioner's side, the board of directors and executive managers can benefit from the implications of this discovery. For example, there is a strong relationship between mechanism structure and IT governance effectiveness $(\beta=0.314)$,

\section{CONCLUSION}

Effective IT governance is of course determined by the way the IT function is organized and where the IT decision-making authority is located within the organization such us Information System Center is structured and its relation to higher reporting levels and other business departments also committee in the higher education there are. In addition, this data article offers implications for policymakers (board of directors) for the implementation of IT governance in order to improve company performance by paying attention to variables in consciousness.

Thus, findings obtained from this research data collection can be used to generate new policies and assist in revising existing policies. 


\section{ACKNOWLEDGMENTS}

This research was supported by Balikpapan University, Balikpapan, Indonesia and Asia E University, Malaysia. This paper is part of the Ph.D. research in school of graduate studies, Asia e University.

\section{REFERENCES}

[1] R. Peterson, "Crafting information technology governance," Inf. Syst. Manag., 2004, doi: 10.1201/1078/44705.21.4.20040901/84183.2.

[2] ISACA and IT Governance Institute, "Global Status Report on the Governance of Enterprise IT (GEIT)-2011," Gov. An Int. J. Policy Adm., 2011.

[3] W. Van Grembergen, S. De Haes, and E. Guldentops, "Structures, Processes and Relational Mechanisms for IT Governance," in Strategies for Information Technology Governance, 2011.

[4] J. W. Ross and P. Weill, "How Top Performers Manage IT Decisions Rights for Superior Results," IT Gov., 2004, doi: 10.2139/ssrn.664612.

[5] P. Subsermsri, K. Jairak, and P. Praneetpolgrang, "Information technology governance practices based on sufficiency economy philosophy in the thai university sector," Inf. Technol. People, 2015, doi: 10.1108/ITP-10-2013-0188.

[6] M. Hicks, G. Pervan, and B. Perrin, "A study of the review and improvement of IT governance in Australian universities in Australian universities," Int. Conf. Inf. Resour. Manag., 2012.

[7] P. Weil and J. W. Ross, "IT Governance: How Top Performers Manage IT," Int. J. Eletronic Gov. Res., 2005, doi: 10.2139/ssrn.664612.

[8] S. Ali and P. Green, "Effective information technology governance mechanisms in public sectors: An Australian case," in PACIS 2006 - 10th Pacific Asia Conference on Information Systems: ICT and Innovation Economy, 2006.

[9] E. N. Nfuka and L. Rusu, "The effect of critical success factors on IT governance performance," Ind. Manag. Data Syst., 2011, doi: 10.1108/02635571111182773.

[10] I. S. Bianchi and R. D. Sousa, "IT Governance Mechanisms in Higher Education," in Procedia Computer Science, 2016, doi: 10.1016/j.procs.2016.09.253.

[11] N. Bajgoric, "Business continuity management: A systemic framework for implementation," Kybernetes, 2014, doi: 10.1108/K-11-2013-0252.

[12] S. Conger, M. Winniford, and L. Erickson-Harris, "Service management in operations," in 14th Americas Conference on Information Systems, AMCIS 2008, 2008.

[13] S. P. J. Wu, D. W. Straub, and T. P. Liang, "How information technology governance mechanisms and strategic alignment influence organizational performance: Insights from a matched survey of business and it managers," MIS Q. Manag. Inf. Syst., 2015, doi: 10.25300/MISQ/2015/39.2.10.

[14] R. Yanosky, "Institutional Data Management in Higher Education,” 2009.

[15] W. Peter and R. Jeanne, "A Matrixed Approach to Designing IT Governance," MIT Sloan Manag. Rev., 2005.

[16] G. L. Lunardi, J. L. Becker, A. C. G. Maçada, and P. C. Dolci, "The impact of adopting IT governance on financial performance: An empirical analysis among Brazilian firms," Int. J. Account. Inf. Syst., 2014, doi: 10.1016/j.accinf.2013.02.001.

[17] R. Pereira, R. Almeida, and M. M. Da Silva, "IT governance patterns in the portuguese financial industry," in Proceedings of the Annual Hawaii International Conference on System Sciences, 2014, doi: 10.1109/HICSS.2014.541.

[18] R. Pereira, M. Mira da Silva, and L. V. Lapão, "Business/IT Alignment through IT Governance Patterns in Portuguese Healthcare," Int. J. It/bus. Alignment Gov., 2014, doi: 10.4018/ijitbag.2014010101. 
[19] W. Van Grembergen and S. De Haes, Enterprise governance of information technology: Achieving strategic alignment and value. 2009.

[20] P. Weill, "IT governance-don't just lead, govern: How top-performing firms govern it," in Strategic Information Management: Challenges and Strategies in Managing Information Systems, 2014.

[21] P. M. A. Ribbers, R. R. Peterson, and M. M. Parker, "Designing information technology governance processes: Diagnosing contemporary practices and competing theories," in Proceedings of the Annual Hawaii International Conference on System Sciences, 2002, doi: 10.1109/HICSS.2002.994351.

[22] S. De Haes and W. Van Grembergen, Enterprise Governance of Information Technology. 2009.

[23] S. De Haes and W. Van Grembergen, "IT governance structures, processes and relational mechanisms: Achieving IT/business alignment in a major Belgian financial group," in Proceedings of the Annual Hawaii International Conference on System Sciences, 2005, doi: 10.1109/hicss.2005.362.

[24] R. Setyadi, A. Subiyakto, and A. B. Abd Rahman, "Assessing the Information Technology Governance Trust Using Readiness and Usability Models: A Model Development Study," in Proceeding - 2018 International Conference on ICT for Rural Development: Rural Development through ICT: Concept, Design, and Implication, IC-ICTRuDEv 2018, 2019, doi: 10.1109/ICICTR.2018.8706852.

[25] P. Weill and R. Woodham, "Don't Just Lead, Govern: Implementing Effective IT Governance," SSRN Electron. J., 2005, doi: 10.2139/ssrn.317319.

[26] C. Ferguson, P. Green, R. Vaswani, and G. Wu, "Determinants of Effective Information Technology Governance," Int. J. Audit., 2013, doi: 10.1111/j.1099-1123.2012.00458.x.

[27] P. Webb, C. Pollard, and G. Ridley, "Attempting to define IT governance: Wisdom or folly?," in Proceedings of the Annual Hawaii International Conference on System Sciences, 2006, doi: 10.1109/HICSS.2006.68.

[28] M. N. Kooper, R. Maes, and E. E. O. R. Lindgreen, "On the governance of information: Introducing a new concept of governance to support the management of information," Int. J. Inf. Manage., 2011, doi: 10.1016/j.ijinfomgt.2010.05.009.

[29] S. Ali and P. Green, "Effective information technology (IT) governance mechanisms: An IT outsourcing perspective," Inf. Syst. Front., 2012, doi: 10.1007/s10796-009-9183y.

[30] G. Heindrickson and C. D. Santos Jr, "Information Technology Governance in Public Organizations: How Perceived Effectiveness Relates To Three Classical Mechanisms," J. Inf. Syst. Technol. Manag., vol. 11, no. 2, pp. 297-326, 2014, doi: 10.4301/s180717752014000200005.

[31] S. Ali and P. Green, "IT governance mechanisms in public sector organisations: An Australian context,” J. Glob. Inf. Manag., 2007, doi: 10.4018/jgim.2007100103.

[32] M. Simonsson and P. Johnson, "Defining IT governance - A consolidation of literature," tEARP Work. Pap. MS103, 2006, doi: 10.1.1.64.6388.

[33] P. Weill and J. W. Ross, "IT Governance on One Page," SSRN Electron. J., 2011, doi: 10.2139/ssrn.664612.

[34] R. Huang, R. W. Zmud, and R. L. Price, "Influencing the effectiveness of IT governance practices through steering committees and communication policies," Eur. J. Inf. Syst., 2010, doi: 10.1057/ejis.2010.16.

[35] N. Mohamed, J. Kaur, and G. Singh, "A conceptual framework for information technology governance effectiveness in private organizations," Inf. Manag. Comput. Secur., 2012, doi: 10.1108/09685221211235616.

[36] A. O. Tonelli, P. H. de Souza Bermejo, P. Aparecida dos Santos, L. Zuppo, and A. L. Zambalde, "It governance in the public sector: a conceptual model," Inf. Syst. Front., 
2017, doi: 10.1007/s10796-015-9614-x.

[37] R. R. Peterson, "Integration strategies and tactics for information technology governance," in Developing Successful ICT Strategies: Competitive Advantages in a Global Knowledge-Driven Society, 2007.

[38] M. S. Aurora Sanchez Ortiz, B.S., Ebook TESTING A MODEL OF THE RELATIONSHIPS AMONG ORGANIZATIONAL PERFORMANCE, IT-BUSINESS ALIGNMENT, AND IT GOVERNANCE. UNIVERSITY OF NORTH TEXAS, 2003.

[39] B. Gu, L. Xue, and G. Ray, "IT governance and IT investment performance: An empirical analysis," in ICIS 2008 Proceedings - Twenty Ninth International Conference on Information Systems, 2008, doi: 10.2139/ssrn.1145102.

[40] H. Ajayi, B.A. Hussin, "ITG_in_University_Practitioners," J. Theor. Appl. Inf. Technol., vol. 88, pp. 219-230, 2016.

[41] M. Soliman and A. H. M. Zaky, "The Mediating Role of IT Governance Effectiveness between ITG and Financial/ Non-Financial Performance: Empirical Research on Egyptian Banking Sector," SSRN Electron. J., 2018, doi: 10.2139/ssrn.3119507.

[42] S. Ali and P. Green, "Determinants of Effective Information Technology Governance : A Study of IT Intensity," Proc. Int. IT Gov. Conf., 2005.

[43] A. Shuhaiber, "The role of perceived control, enjoyment, cost, sustainability and trust on intention to use smart meters: An empirical study using SEM-PLS," in Advances in Intelligent Systems and Computing, 2018, doi: 10.1007/978-3-319-77712-2_74.

[44] C. M. Ringle, M. Sarstedt, and D. W. Straub, "A critical look at the use of PLS-SEM in MIS quarterly," MIS Quarterly: Management Information Systems. 2012.

[45] F. Quoquab, S. Pahlevan, J. Mohammad, and R. Thurasamy, "Factors affecting consumers' intention to purchase counterfeit product," Asia Pacific J. Mark. Logist., 2017, doi: 10.1108/apjml-09-2016-0169.

[46] N. Venkatraman, J. C. Henderson, and S. Oldach, "Continuous strategic alignment: Exploiting information technology capabilities for competitive success," Eur. Manag. J., 1993, doi: 10.1016/0263-2373(93)90037-I.

[47] S. S. Maidin and N. H. Arshad, "IT governance practices model in IT project approval and implementation in Malaysian public sector," in ICEIE 2010 - 2010 International Conference on Electronics and Information Engineering, Proceedings, 2010, doi: 10.1109/ICEIE.2010.5559690.

[48] A. O. Tonelli, P. H. de Souza Bermejo, P. Aparecida dos Santos, L. Zuppo, and A. L. Zambalde, "It governance in the public sector: a conceptual model," Inf. Syst. Front., 2017, doi: 10.1007/s10796-015-9614-X. 